\title{
The Current Status and Development Countermeasures of Online Pharmacies in China
}

\author{
Xijin Chen \\ Management School, Jinan University, Guangzhou, China \\ Email:610760533@qq.com
}

How to cite this paper: Chen, X.J. (2018) The Current Status and Development Countermeasures of Online Pharmacies in China. Open Journal of Social Sciences, 6, 224-231.

https://doi.org/10.4236/jss.2018.64019

Received: April 8, 2018

Accepted: April 25, 2018

Published: April 28, 2018

Copyright $\odot 2018$ by author and Scientific Research Publishing Inc. This work is licensed under the Creative Commons Attribution International License (CC BY 4.0).

http://creativecommons.org/licenses/by/4.0/

\section{(c) (i) Open Access}

\begin{abstract}
Objective: To propose countermeasures for online pharmacies and promote the development of online pharmacies in China. Method: To summarize development status of China's online pharmacies through literature analysis. The number of online pharmacies in China has increased year by year, and China's policies have gradually opened up. However, there's still imperfect situation in the medicine quality, pharmaceutical care, logistics and distribution, unopened OTC medicines, the online pharmacies are not docked with the social insurance, and other issues that hinder the development of online pharmacies. Results and Conclusion: Online pharmacies enhance corporate self-discipline, and establish third-party logistics, thus to improve the quality of the pharmaceutical care, gradually opening OTC medicine sales, achieve the docking with the social insurance system and others to promote the development of online pharmacies in China.
\end{abstract}

\section{Keywords}

Online Pharmacies, Pharmacy Management, Medicine Quality, Logistics and Distribution, Pharmaceutical Care

\section{Introduction}

With the rapid development of e-commerce, the number of online shopping populations is increasing. At the same time, in order to ease the current domestic medical tensions, online pharmacies based on pharmaceutical e-commerce have emerged. Since the first online pharmacy officially emerged, the online pharmacies in China have developed for over 10 years. But their market acceptance is still not high, and is still at the initial stage of market development. So 
we need to analyze the Current Status and management of online pharmacies in China, and find the reasons of slow development to propose countermeasures for online pharmacies.

Online pharmacies refer to the electronic virtual sales market legally established by the enterprises that can realize the pharmaceuticals trade with individual consumers on the Internet. The online pharmacies are an important component of the medical electronic commerce, and belong to the electronic commerce model of business to customer (B2C). Their main functions are to realize online medicine retails and online pharmaceutical care, the products operated include OTC medicines, dietary supplements, family planning supplies, health food and medical apparatus.

\section{Development Status of Online Pharmacies in China}

\subsection{A Great Increase in the Number of Online Pharmacies}

Since China's first online pharmacy emerged in December 2005, the number of online pharmacies in China has grown rapidly year by year, as shown in Figure 1 , and the online pharmacies have grown to nearly 700 by 2018 . Overall, the online pharmacies in China have continued to grow year by year since 2005.

As of March 2018, according to official website data of China Food and Drug Administration (CFDA), there were 991 companies that obtained Internet Medicine Trading Service Qualification, including 54 online pharmacies were A-licensed, and their service scope was "a third-party trading service platform." 244online pharmacies were B-licensed, their service scope was "to conduct medicine transactions with other companies," and 693 were C-licensed, their service scope was "to provide individual consumers with medicines."

As of March 2018, there were a total of 693 online pharmacies in China, but they were in uneven regional distribution, showing a pattern that there were more online pharmacies in southern regions and fewer in northern regions, and the number of online pharmacies was reduced from southeastern coastal areas to the northwest inland. As shown in Figure 2, the five provinces and cities of Guangdong, Jiangsu, Zhejiang, Shandong, and Beijing accounted for 52\% of the total online pharmacies in China. Guangdong was with the highest number of 150 online pharmacies, accounting for $22 \%$ of the total number of online pharmacies in China.

\subsection{Gradual Opening of National Policy}

In recent years, China's national policy environment has been gradually relaxed and online pharmacies market development has been faced with great opportunities and development prospects.

In July 2015, the State Council pointed out in the Instructions on Actively Promoting "Internet+" Action [1]: It's essential to promote the development of a new model of online medical and health services, and to use the Internet to establish an information sharing platform. With implementation of "Internet + 


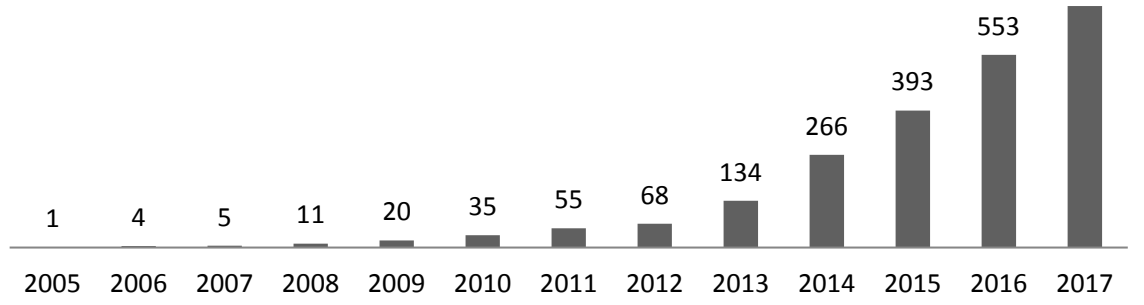

Figure 1. Changes in the number of online pharmacies in China.

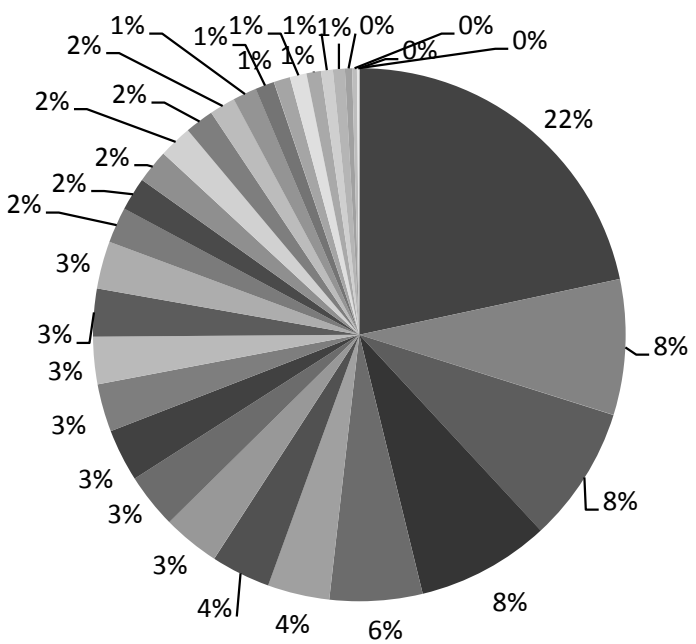

\begin{tabular}{|c|c|c|c|c|}
\hline Guangdong & - Jiangsu & - Zhejiang & Shandong & Beijing \\
\hline Sichuan & Chongqing & Fujian & Anhui & - Henan \\
\hline Hebei & Liaoning & Shanghai & Jiangxi & Hubei \\
\hline a Jilin & Hunan & Guangxi & - Heilongjiang & Guizhou \\
\hline Shanxi & Yunnan & Tianjin & Shanxi & Gansu \\
\hline Inner Mongoli & Hainan & Xinjiang & Qinghai & Ningxia \\
\hline
\end{tabular}

Figure 2. Regional distribution of China's online pharmacies.

medicine", online medicine sales and medical services of online pharmacies can further simplify the circulation, and reduce costs, thus to meet the diversified needs of consumers, and there are huge market development prospects in the future.

In January 2017, the State Council issued the Decision Regarding Cancelling the Third Batch of Administrative Approvals Implemented by the Centrally-Designated Places [2]. In the decision, China cancelled the approval of B license and $C$ license in the qualification of the Internet medicine trade and reduced the threshold for online pharmacies to enter the market in the future. This 
has also brought more room for the rapid development of China's online pharmacies.

\subsection{Small Number of Online Shopping Users}

The market for online pharmacies in China is vast, but it does not provide the necessary development momentum. According to iResearch iUser Tracker monitoring data [3] display that the user traffic of the medical e-commerce business and the overall scale of online shopping users with nearly 400 million users are still small, and the online medicine consumption market still has a lot of room for development. The proportion of medical e-commerce users in the overall online shopping users accounted for $26.3 \%$, and non-medical e-commerce users accounted for $73.7 \%$ [4]. The proportion of pharmaceutical e-commerce users in the overall online shopping users is relatively low, and there is still a large market space. And many people have said that they have browsed internet drug information, but few people buy drugs through online pharmacies.

\section{Problems of Online Pharmacies Existed in China}

The reasons and problems concerning the slow development of online pharmacies and the low market acceptance rate deserve our attention.

\subsection{Difficult to Guarantee the Medicine Quality}

According to a CNNIC survey, the primary issue for online transactions is product quality. Some illegal online pharmacies sell fake medicines, inferior medicines or even the contraband medicines. Due to the fact that most consumers lack the professional knowledge of medicines, it is difficult to discern the authenticity of online pharmacies, resulting in frequent occurrences of cheated incidents, and the consumers will blame related responsibilities to the entire online pharmacies market [5]. The illegal online pharmacies directly lead to a crisis of trust for many online pharmacies. In addition, the purchase of medicine in a physical pharmacy is visible and tangible, which will make consumers to be more at ease, and the virtuality of online pharmacies will cause consumers to have many concerns and worries. Consumers cannot determine the quality of medicines, and the medicines are related to human life and health problems, which will seriously affect the attitude of consumers on the Internet.

\subsection{Imperfect Logistics and Distribution Channels}

Medicine is a special commodity, and the consumers purchasing medicines are often for urgent use, and their needs for the medicines are timely. When online pharmacies arrange the medicine distribution, especially for the distribution to different places, it usually takes 1 to 3 days, and sometimes even longer, which is difficult to meet the eager needs of consumers. It is better to go to physical pharmacies to buy medicine. In addition to slow distribution logistics, the specialty of medicine storage conditions also has high requirements for distribution. 
In distribution process, the medicine must be kept in proper temperature, humidity, corrosion protection, and drop resistance, etc. According to Article 9 of the Provisional Regulations on the Approval of Internet Medicine Trading Services [6], the enterprises that provide Internet medicine trading services to individual consumers should have a medicine distribution system that is compatible with the trading types on the Internet. Currently, only a few Internet medicine trading service companies in China have their own logistics companies. All other online pharmacies adopt the third-party logistics companies for medicine distribution. However, most of these logistics companies have not passed GSP certification, and so it's inevitable to avoid the damage, pollution, exchange, or deterioration of medicine during distribution. There's no way to guarantee medicine quality in terms of the medicine distribution, which is with a great safety risk.

\subsection{Pharmaceutical Care Needs to Be Improved}

Due to the limitation of personal knowledge of consumers, there are often unknown cases of medication, so online pharmacies are urgently required to provide online pharmaceutical care, and offer the medication safety alert services to guide the safe medication [7]. At present, the service time for most of the online pharmacies licensed Pharmacists are from about 9 am to $10 \mathrm{pm}$, which is basically the same as the operating hours of the most physical pharmacies. However, the majority of online pharmacies consumers are young and middle-aged people who are at work. Usually, they only have time to buy medicine from online pharmacies after work or overtime work, and they may not have private time to buy medicines until after 10:00 pm. Obviously, the range of service time of licensed pharmacists for online pharmacies is not in line with the spending habits of major consumer groups. Furthermore, the online pharmacies licensed pharmacist's ability of medication guidance of online pharmacies licensed pharmacist is not so satisfactory, the licensed pharmacists are with low qualification level, making pharmaceutical care function of online pharmacies cannot be realized smoothly with the help of licensed pharmacists, and it is difficult to change operating model from sales-oriented to service-oriented.

\subsection{OTC Medicines Cannot Be Sold}

According to Article 21 of Provisional Regulations on Approval of Internet Medicine Trading Services [6]: Enterprises providing individual consumers with Internet medicine trading services can only sell non-OTC medicines operated by company through online. Furthermore, non-OTC medicines account for only a small fraction of total quantity of medicines. Many diseases are needed to be cured by the use of OTC medicines. The market share of OTC medicines in China is 800 billion yuan, while non-OTC medicines are only 200 billion yuan of the market share [8] If the market of OTC medicines is not open, online pharmacies only rely on sales of non-OTC medicines, dietary supplements and medical apparatus, which leads the online pharmacies to lose a large part of the 
market, and difficult to develop quickly and healthily.

\subsection{Medical Insurance Cannot Be Used}

There's huge development space of the Internet medicine trading market in China, but the medicine trading itself is strictly controlled by the national policies. The policy of "social insurance cannot be used for paying the medicines purchased from the online pharmacies" has become the biggest barrier that the industry can't be vigorously promoted. At present, the coverage of social insurance in China has risen to more than 95\% [9]. Realizing the docking of online pharmacies with social insurance payment system will be a huge breakthrough for the entire Internet medicine sales market. Greater discounts can be enjoyed by purchasing medicine through the social insurance, most of the physical pharmacies have realized the docking with the social insurance system, and the fact that social insurance cannot be used in the online pharmacies has made them lose a large part of consumers who enjoy social insurance.

\section{Countermeasures for the Development of Online Pharmacies in China}

\subsection{To Strengthen the Self-Discipline of Online Pharmacies}

Integrity is an important factor for businessmen to attract consumers, and it is also the confusion of current consumers about online pharmacies. Legal online pharmacies should strengthen self-discipline to ensure product quality and service quality. There should be neither false propaganda, nor sales of counterfeit medicines. In addition, the product information such as pictures and text should be consistent with the actual situation of the product. The medicine should be delivered in a timely manner, there should be the agreement signed with the consumers before payment, if the medicines were not received within the term of the agreement, a full refund to the consumers will be conducted. The after-sales services of online shopping should be guaranteed, consumers should not find excuses when there's any quality issue in the online shopping medicine, such issues should be solved timely, so as to reduce consumer purchase risk as much as possible, and improve customer satisfaction, and also establish a good image of online pharmacies.

\subsection{To Establish Third-Party Professional Logistics}

If it's insisted that each online pharmacy should build their own distribution system and achieve a wide range of regional coverage in China, the cost will be very large and difficult to realize, this will seriously affect the development of online pharmacies in China. Therefore, seen from the status in China, the most economical and scientific approach is to guide third-party logistics companies as soon as possible to establish a professional logistics team that meets medicine distribution through GSP certification, and ensure that the online medicine distribution is safe, convenient, and efficient, thus to realize the new model of 
"buying medicine from online pharmacies + third party logistics distribution".

\subsection{To Improve the Quality of Online Pharmaceutical Care}

In order to improve the quality of online service online pharmacies on our hospital, we can improve the online customer services' pharmaceutical care quality of online pharmacies, the improvement can be made from following two aspects: to improve the access qualification of online customer service, and conduct the regular training assessments to ensure the level of professional knowledge and the full play of online pharmacies. People's medicine safety should be guaranteed; extending the online customer service time, thus to ensure that the online customer services are available throughout 24 hours, and that consumers can consult at any time to seek medication guidance.

\subsection{To Gradually Open the Sales of OTC Medicines}

From the perspective of long-term development, it's inevitable trend for the online pharmacies in China to sell OTC medicines. Since consumers have a certain demand for buying OTC medicine through online pharmacies, online pharmacies also have great enthusiasm for selling OTC medicines. In this regard, the relevant departments of China should proceed from the following points: Continuing to deepen the new medical reform, promoting the construction of medical information, allowing the hospitals to circulate prescriptions outside, then is to promote the docking between online pharmacies and electronic prescription libraries of medical institutions to solve the source problem of electronic prescriptions. The regular online pharmacies should be chosen as a pilot company, some OTC medicines sales are opened by taking safety, effectiveness, stability and ease of use as the selection principles, the online sales of OTC medicines catalog should be developed, and the operating model for online pharmacies to sell OTC medicines should also be explored.

\subsection{To Realize the Docking with Social Insurance System}

The establishment of social insurance self-service payment platform for the online pharmacies will be the inevitable trend of online pharmacies development in China. In order to achieve this goal, it is necessary to start from the following two aspects: The Ministry of National Human Resources and Social Security implements the national unified social insurance card to replace local self-made social insurance cards, thus to make an end of the current status that the social insurance cards cannot be used in all provinces and municipalities. This measure is to realize the one card solution for the national social insurance, thus to provide the foundation for the establishment of the self-service payment platform of online pharmacies social insurance. The CFDA communicates with the Ministry of Human Resources and Social Security to implement the docking of online pharmacies with the social insurance system as soon as possible, and implements social insurance consumer card for buying medicine from online pharmacies. 
It's necessary to build self-service payment platform of online pharmacies social insurance, thus to facilitate payment of online medicine purchases by insured personnel and promote transformation of China's pharmacies e-commerce payment methods.

\section{Conclusion and Implications}

With the rapid development of e-commerce, the development of online pharmacies has become a general trend, but it also faces great opportunities and challenges. It's essential to fully play the advantages of online pharmacies and continuously solve the problems in development, thus to provide consumers with a safe and convenient shopping environment. It's necessary for online pharmacies to continuously explore new countermeasures and innovate business models, thus to achieve better and faster development.

\section{References}

[1] The State Council of the People's Republic of China (2015) Instructions on Actively Promoting "Internet+" Action. http://www.gov.cn/zhengce/content/2015-07/04/content_10002.htm

[2] The State Council of the People's Republic of China (2017) Cancelling the Third Batch of Administrative Approvals Implemented by the Centrally-Designated Places. http://www.gov.cn/zhengce/content/2017-01/21/content_5161879.htm

[3] IResearch (2015) China's Pharmaceutical e-Commerce Industry Development Research Report. http://www.iresearch.com.cn/report/2479.html

[4] IResearch (2015) China Pharmaceutical E-Commerce User Behavior Research Report. http://report.iresearch.cn/report/201512/2505.shtml

[5] Li, Y., Dou, J.L. and Zhang, L.Q. (2017) On the Problems of Online Pharmacies in China. Chinese Pharmaceutical Affairs, 31, 727-732.

[6] State Food and Drug Administration (2005) Provisional Regulations on the Approval of Internet Medicine Trading Services. http://www.sda.gov.cn/WS01/CL0060/9432.html

[7] Xie, M. and Zhao, M. (2016) Investigation and Analysis of Online Pharmacy Pharmacist Service in China. China Pharmacy, 27, 2452-2455.

[8] Liang, X.Y. and Feng, G.Z. (2015) Online Pharmacies Sell Prescription of Medicine Mode. Central South Pharmacy, 13, 446-448.

[9] Lv, X.C. and Deng, Y. (2016) Online Pharmacies Health Care Payment Barriers and Countermeasures in China. China Pharmacy, 27, 573-576. 